\title{
JUEGO ELECTORAL Y RELACIONES POLÍTICAS EN EL FÚTBOL ARGENTINO*
}

Jogo eleitoral e relações políticas no

futebol argentino

Electoral game and politics relations in the Argentinian football

María Verónica Moreira**

\begin{abstract}
RESUMEN
El propósito de este trabajo es analizar las relaciones que los dirigentes, los hinchas y los políticos de otros espacios sociales crean y/o fortalecen durante las elecciones en un club de fútbol. Los procesos electorales son eventos ideales para observar con nitidez la formación de relaciones de alianza y clientela entre los actores sociales nombrados. Este contexto, además, nos permite identificar algunas de las prácticas que caracterizan a "la política tradicional". Por ejemplo, es posible observar cómo los hinchas politizados buscan adherentes, consiguen votos, arrastran los votos hacia un candidato, mientras que los aspirantes a los puestos directivos de la institución realizan o prometen obras de interés público, buscan el apoyo de individuos influyentes, etc. Precisamente, entre los individuos influyentes que brindan apoyo a los dirigentes y/o candidatos, están los políticos que provienen de otros espacios sociales (de la política local y de los sindicatos de trabajadores). La posición estratégica de dichos individuos, que participan simultáneamente en esferas de actuación distintas (fútbol y sindicato; fútbol y política local), agiliza la articulación entre distintos campos y la circulación de ayudas en beneficio del club. La participación de estos actores no se produce únicamente por el interés de acercarse a un deporte popular que reditúa políticamente, sino también, por el afecto y la pasión que sienten por el club.
\end{abstract}

Palabras-clave: fútbol; política; relaciones.

La investigación que respalda este trabajo fue financiada con fondos de la UBA(Programa UBACYT), el Foncyt (Programa PICT) y el CONICET.

** Instituto de Investigaciones Gino Germani/Universidad de Buenos Aires y el CONICET. 


\title{
RESUMO
}

O propósito deste trabalho é analisar as relações que dirigentes, torcedores e políticos de outros espaços sociais criam e/ou fortalecem durante as eleições em um clube de futebol. Os processos eleitorais são eventos ideais para se observar com nitidez a formação de relações de aliança e clientelismo entre os atores sociais nomeados. Este contexto, além disso, nos permite identificar algumas das práticas que caracterizam a "política tradicional". Por exemplo, é possível observar como os torcedores politizados buscam adeptos, conseguem votos, arregimentam votos para um candidato, enquanto que os aspirantes aos postos diretivos da instituição realizam ou prometem obras de interesse público, buscam o apoio de indivíduos influentes etc. Precisamente, entre os indivíduos influentes que fornecem apoio aos dirigentes e/ou candidatos estão os políticos que provêm de outros espaços sociais (da política local e dos sindicatos de trabalhadores). A posição estratégica desses indivíduos que participam simultaneamente de esferas de atuação distintas (futebol e sindicato; futebol e política local) agiliza a articulação entre campos distintos e a circulação de ajudas em benefício do clube. A participação destes atores não se produz unicamente pelo interesse de se aproximar de um esporte popular que renda politicamente, senão também pelo afeto e paixão que sentem pelo clube.

Palavras-chave: futebol; política; relações.

\begin{abstract}
The aim of this project is to analyze the relation that the sport leaders, fans and politicians from other social fields create or improve during the electoral politics process in a sport institution. The electoral politics processes are the perfect events to discover the creation of alliances and clientele between these social agents. This context also allows us to identify some of the practice of the "traditional politics". For example, is possible to find out how the fans - who are related to the politic situation - look for adherents, get votes or turn out those votes for one candidate, as the applicants to become managers of the sport institution do or promise works of public interest or even look for the support of influential and important people. Precisely, between the group of influential people who give support to sport leaders or candidates, we can stumble on the politicians that come from other social fields (from the local politics and from the labor union groups). The strategic position of this kind of people - who participate simultaneously in diverse areas (like football and labor union groups; football and local politics) - improve the relationship between different fields and even help giving benefits
\end{abstract}


to the club. The participation of this actors is it possible because this kind of people is especially interested in becoming a political part of a popular sport institution (as a sport leader) and also cause they support that club as a fan of it.

Key-words: football; politics; relations.

\section{Introducción}

Las relaciones entre el mundo social del fútbol y la dimensión política pueden comprenderse desde distintas perspectivas. En esta ocasión, decidimos pensar dicha relación a partir de la posibilidad que da el formato jurídico de los clubes en Argentina para el desarrollo de "lo político". El formato que organiza las instituciones deportivas en nuestro país es el de la asociación civil. Esto implica que cada tres o cuatro años, tal vez menos, en dichas entidades comience una movilización importante de recursos para la elección de los dirigentes que conducirán los designios de las asociaciones por un tiempo determinado. Los hinchas también participan del proceso electoral votando y/o ayudando a los candidatos a conseguir los votos necesarios para obtener los cargos directivos. Llegar a la dirección de los clubes implica el despliegue de una serie de prácticas muy parecidas a las que se producen en el ámbito de la política tradicional. Durante los procesos electorales, los hinchas y los dirigentes agudizan las interacciones cotidianas para formar o reforzar las alianzas y las relaciones clientelares.

Otra manera de pensar "lo político" en el fútbol es estudiar la participación de individuos, originalmente ajenos a él, que provienen de otros campos como el campo de la política local y la política sindical. En el análisis de la circulación - y la simultaneidad de prácticas - de los individuos que se encuentran en distintas esferas de actuación, sugerimos tanto la hipótesis instrumental como la afectiva. Es decir, el ingreso de los funcionarios del Estado y los sindicalistas - de gremios que agrupan a los trabajadores - al fútbol puede entenderse como una necesidad de mostrarse públicamente cerca de los clubes reconocidos para engrandecer su popularidad, y también como parte del afecto y la pasión que ellos sienten por estas instituciones. Las inclinaciones futbolísticas de los actores juegan a favor de las entidades 
que aprecian. Por otra parte, las relaciones que se crean entre los dirigentes deportivos y "los políticos profesionales", representativos de otros campos, permiten la construcción de puentes a través de los cuales circulan ayudas, préstamos y favores hacia los clubes.

El propósito de este trabajo es describir y analizar a partir de un caso localmente situado en Argentina, las relaciones que los dirigentes, los hinchas y los políticos de otros espacios crean y/o fortalecen durante el tiempo electoral. Éste es un momento especial en el marco del cual, las alianzas y las clientelas se forman y cristalizan para que los candidatos a los puestos directivos puedan ganar las elecciones. En este contexto, es posible observar un despliegue de prácticas asociadas a lo que comúnmente se denomina "la política tradicional": organizar actos electorales, buscar adherentes, formar facciones, conseguir votos, realizar o prometer obras de interés público, etc. Algunas de estas prácticas aparecen en el trabajo a través de la descripción y el análisis propuestos.

Los datos etnográficos que dan sustento al presente estudio surgen de una investigación realizada en una institución deportiva, de reconocida trayectoria en el fútbol profesional de Argentina, que aquí llamamos Club Atlético Juventud Unida ${ }^{1}$ (CAJU). El club se encuentra en el municipio del Conurbano Bonaerense conocido como Pontevedra, ${ }^{2}$ al sur de la Ciudad Autónoma de Buenos Aires. El trabajo de campo se prolongó a lo largo de diez años, aunque tuvo en su recorrido algunas pausas. En esta ocasión, consideramos especialmente las incursiones etnográficas realizadas en los años 2004 y 2005 y desde mediados de 2007 hasta fines de 2009 - períodos en los que estudiamos los pormenores de los procesos electorales en la institución deportiva.

1 En bastardilla se encuentran las categorías nativas que luego de su presentación tendrán el formato general del texto.

2 Se denomina Conurbano Bonaerense a la zona constituida por los municipios de la provincia de Buenos Aires que rodean a la Ciudad Autónoma de Buenos Aires, centro administrativo del país. En este artículo, hemos modificado los nombres del municipio, del club donde se realizó la investigación y de las personas sobre y con las trabajamos en la etnografía. 


\section{¿De qué hablamos cuando hablamos de "la relación fútbol y política"?}

"La relación entre fútbol y política" es un tópico recurrente en los medios de comunicación masivos. Los abordajes mediáticos tratan la temática haciendo foco sobre determinados aspectos del fenómeno. Por ejemplo, centralizan la mirada en el uso que los agentes de otros espacios socales (a saber: políticos, sindicalistas, empresarios) hacen del fútbol para saltar a una posición de poder superior. Estos individuos se acercarían a las entidades con un alto nivel de popularidad con el ánimo de acaparar recursos que luego traducirían en un ascenso de posiciones y una ganancia de poder. Por otra parte, hay quienes sugieren que dichos individuos ingresan al mundo del fútbol solamente con la intención de concretar negocios económicamente rentables para sí. Pero, estos individuos, originalmente ajenos al deporte, también favorecen a los clubes de fútbol canalizando regularmente distintos tipos de asistencia por el amor que sienten hacia ellos. Así, es preciso reconocer en el abordaje de dichos actores la coexistencia de una dimensión instrumental (que enfatiza el uso del fútbol para obtener un beneficio personal) y una dimensión afectiva.

Asimismo, el clientelismo político es otro tópico que los medios introducen en torno a los hinchas que integran las barras o las hinchadas ${ }^{3}$ (conocidas popularmente como "barras bravas"). En este caso, los medios de comunicación refuerzan la hipótesis sobre la manipulación que hacen los dirigentes de los hinchas, que se caracterizan por hacer de la violencia un rasgo de su identidad. Los hinchas serían convocados por los candidatos durante las elecciones para realizar tareas asociadas a la fuerza y a las

3 Las barras son grupos organizados de fanáticos que se caracterizan por valorizar positivamente las peleas contra sus rivales futbolísticos. En otros trabajos, hemos estudiado en profundidad la categoría nativa el aguante que refiere al valor que los hinchas deben mostrar cuando se enfrentan físicamente a los adversarios. Ver ALABARCES, Pablo. Crónicas del aguante. Fútbol, violencia y política. Buenos Aires: Capital Intelectual, 2004. GARRIGA ZUCAL, José. "Soy Macho porque me la aguanto". Etnografía de las prácticas violentas y la conformación de identidades de género masculino. In: ALABARCES, Pablo et al. (Org.). Hinchadas. Buenos Aires: Prometeo, 2005. GARRIGA ZUCAL, José; MOREIRA, María Verónica. El aguante: Hinchadas de fútbol entre la pasión y la violencia. In: MIGUEZ, Daniel; SEMAN, Pablo (Org.). Entre santos, cumbias y piquetes. Las culturas populares en la Argentina reciente. Buenos Aires: Biblos, 2006. MOREIRA, María Verónica. Trofeos de guerra y hombres de honor. In: ALABARCES, Pablo et al. (Org.) Hinchadas. Buenos Aires: Prometeo, 2005. 
destrezas de sus cuerpos: intimidación, amenaza, protección, etc. Generalmente, las representaciones mediáticas se construyen en base a la idea de la irracionalidad de las prácticas de los hinchas a través de categorías tales como "animales", "salvajes" y "bárbaros". Esto sugiere una expulsión del plano de la cultura y una reconversión de dichos sujetos en meros objetos de los agentes ubicados en posiciones legítimas. Sin embargo, los hinchas también son valorados en las elecciones por motivos distintos a los de su apoyo físico. Ellos ingresan al juego político como aliados y clientes en razón de su capital social.

¿Qué más podemos decir sobre la "relación entre fútbol y política?

Lejos de ser un fenómeno que invade y contamina el campo del deporte, "la política" es un elemento que lo constituye dinámicamente. Podemos desagregar la pregunta sobre cómo la política dinamiza el campo del fútbol en dos dimensiones. Una que refiere a la posibilidad que brinda el modelo jurídico imperante en los clubes de fútbol nacionales: la asociación civil sin fines de lucro. A diferencia de los clubes de las ligas europeas que son mayoritariamente empresas comerciales, las instituciones que están afiliadas a la Asociación de Fútbol Argentino (AFA) se encuentran administradas por dirigentes amateurs, ${ }^{4}$ que son elegidos según las reglas de sus respectivos estatutos sociales entre miles de socios. La fortuna es el factor que facilita el ingreso de los empresarios a la dirección de las entidades europeas. En Argentina, el capital económico es una variable importante - pues los dirigentes gozan de un tiempo de trabajo liberado -, pero los interesados en acceder a la conducción lo hacen a través de mecanismos y estrategias electorales. Idealmente, todos los socios tienen el derecho de participar en las elecciones como candidatos a dirigente. Cabe señalar que sólo un sector de la masa total de afiliados, que en los clubes más importantes del país supera las 30.000 personas, se dedica a participar de la política institucional como candidato y/o elector.

La elección de los dirigentes en el CAJU se realiza cada tres años. Los socios ${ }^{5}$ eligen una lista en la que se detallan los nombres de los

4 El trabajo de los dirigentes no recibe remuneración, por eso es conocido como una actividad "amateur". Este principio nació de la filosofía de la asociación civil sin fines de lucro que resalta las colaboraciones desinteresadas de sus miembros en beneficio de los intereses colectivos de la institución.

5 Si bien todos los socios del club no son hinchas de Juventud-porque ciertos individuos ajenos al fútbol se asocian a la institución para practicar deportes y/o intervenir en las actividades que ésta 
candidatos a la Comisión Directiva que está formada por el Presidente - la máxima autoridad -, dos Vicepresidentes, varios Secretarios y Vocales; la Comisión Revisora de Cuentas en la que tres dirigentes controlan los movimientos económicos de la institución; y los Representantes de Socios que se reúnen dos o tres veces por año para confirmar o rechazar los informes de la Comisión Directiva. Este último sector está compuesto por 90 socios que se dividen entre los que representan al gobierno y los que representan al resto de las listas que no salieron ganadoras en la elección.

Los dirigentes juegan en un espacio que está signado por la competencia con los adversarios políticos. Aquellos que gobiernan el club traban una lucha contra los representantes de las agrupaciones políticas ${ }^{6}$ adversarias que tienen como meta acceder al poder político que ellos conservan. Oficialistas y opositores ponen en juego sus aptitudes y habilidades para mantener, aumentar o ganar posiciones en la arena de lucha. Allí se producen combates y enfrentamientos entre los dirigentes de turno y los socios que aspiran a sucederlos en los cargos jerárquicos. La pelea entre los interesados en ocupar posiciones de dirección se traba también en función de la captura del apoyo de los hinchas, que son los receptores directos de las decisiones tomadas en torno al fútbol y a otras actividades del club. Así, siguiendo a Bourdieu (2007), " "el campo político" de los dirigentes se estructura en términos de una lógica doble, interna y externa. La primera alude a los intereses específicos de los socios politizados que luchan entre sí, mientras que la segunda refiere a la toma de posición frente a los intereses de los hinchas. Con éstos se justifica la pregunta sobre "¿para quiénes hacer política?". Los hinchas son los destinatarios de los programas, los proyectos y las promesas de los dirigentes y sus rivales. Una vez que asumen los cargos directivos, los dirigentes, para evitar profundos cuestionamientos a sus gestiones, precisan que sus discursos y sus acciones concuerden en

ofrece -, la mayoría de ellos sigue los avatares del equipo profesional. A su vez, todos los hinchas del CAJU no son socios del club. La elección de usar las categorías hincha o socio de manera indistinta responde a que interactuamos en el trabajo de campo con individuos que respondían a ambos términos, y a que el foco del trabajo está puesto en marcar la posición asimétrica entre ellos y los dirigentes.

6 Una agrupación política es una organización que congrega a un sector de los socios del CAJU que están interesados en encauzar una acción común que tiende a la conquista del poder político en la institución. Una lista puede ser el resultado de una alianza entre varias agrupaciones políticas.

7 BOURDIEU, Pierre. O poder simbólico. Río de Janeiro: Bertrand, 2007. 
algunos puntos, como dice Frederic (2004) ${ }^{8}$ con las expectativas de una comunidad de referencia formada, en este caso, por los hinchas.

Las jugadas de los dirigentes nunca se dan aisladamente, ellos entablan relaciones y establecen alianzas con figuras representativas de otras esferas de actuación. ${ }^{9}$ Un recurso político de los dirigentes es la exhibición de un set de relaciones influyentes que opera como capital social durante las elecciones. La segunda dimensión que permite analizar cómo la política dinamiza el fútbol es, precisamente, comprender las conexiones entre "el adentro" y "el afuera" del campo deportivo. Un "adentro" que, muchas veces, se beneficia de las acciones de las personalidades originalmente ajenas a él.

\section{Entre campos: fútbol, sindicato y política local}

Una forma de estudiar las intersecciones entre el mundo del fútbol y la política es a través del análisis situado: las relaciones y las alianzas que los dirigentes deportivos del CAJU establecen con los políticos del gobierno municipal de Pontevedra y los referentes de un sindicato nacional. A partir de estos casos observamos que algunos individuos con una doble adscripción - en representación del club y de un sindicato o municipio - agilizan la articulación entre distintos espacios sociales, los que se encuentran lógicamente - separados sólo en términos analíticos.

Desarrollar una gestión exitosa en un club de primera línea como el CAJU repercute positivamente en la construcción de la imagen de los dirigentes que desean probar suerte en otros espacios de poder. Los dirigentes deportivos que tienen éxito en el ámbito futbolístico pueden reconvertir su fama y prestigio en recursos útiles para la participación en espacios de poder alternativos. Es común que los dirigentes con trayectorias exitosas sean convocados como funcionarios del Estado (municipal, provincial o

8 FREDERIC, Sabina. Buenos vecinos, malos políticos. Moralidad y politica en el Gran Buenos Aires. Buenos Aires: Prometeo, 2004.

9 BOURDIEU, Pierre. Razones prácticas. Sobre la teoría de la acción. Barcelona: Anagrama, 1997. 
nacional), como candidatos de partidos políticos; o que ellos mismos impulsen sus carreras para acceder a los cargos públicos. Los casos inversos también son posibles: personalidades cuyo prestigio se ha construido en otros campos son convocados para participar del escenario institucional del CAJU en virtud de su reconocimiento. Unos y otros tejen lazos que facilitan la circulación de bienes y servicios a favor de la entidad deportiva.

Durante la campaña política que se inició en el club hacia fines de 2004, Facundo Ramos, que conducía el área del fútbol profesional, se perfiló como un candidato prometedor para ocupar la presidencia de la institución. Ramos convocó a una popular figura del campo de los sindicatos en Argentina para que lo acompañara en la lista: Juan Manuel García. El sindicalista tenía un extenso recorrido en la historia de los sindicatos nacionales, destacándose primero - como militante y luego como líder - de un sector particular ${ }^{10}$ y posteriormente, hacia 2005, convirtiéndose en un referente del movimiento de trabajadores argentinos, de la CGT (Confederación General del Trabajo). El ingreso de García a la política institucional del club se oficializó cuando en abril de 2005 la fórmula encabezada por Facundo Ramos le ganó por un pequeño margen a la lista de Minas Akiam. El sindicalista ingresó al club para ocupar un puesto en el bloque de Representantes de Socios oficialista y su hijo Pedro, también dirigente del sindicato, se consagró como vocal titular de la Comisión Directiva.

A partir de la influencia de los sindicalistas, se hicieron una serie de refacciones en el complejo Santa Rita, un predio de varias hectáreas ubicado en Pontevedra que está destinado al entrenamiento del equipo profesional de fútbol y de las categorías inferiores. Allí, se pusieron en marcha distintas obras financiadas por el sindicato: arreglos en la confitería y en el sector de los vestuarios así como también se construyeron dos oficinas y una sala de prensa. Como los jugadores de las categorías inferiores, que provienen en su mayoría de las provincias del interior del país, residen en el complejo, fue un acierto de los sindicalistas hacer del lugar un espacio más confortable con sala de juegos, video, internet y televisión.

10 Nos referimos al sector gremial que representa García de forma general como el sindicato, sin revelar la rama de trabajo específica en la que se destaca. Por otra parte, adoptamos el término sindicalista(s) para mencionar a los líderes y a los seguidores de dicho gremio. 
Juan Manuel García ayudó a refaccionar las instalaciones del predio Santa Rita y también logró un acuerdo para comprar las tierras de dicho lugar. El CAJU le alquilaba desde hacía varios años el predio a la CEAMSE. ${ }^{11} \mathrm{La}$ intervención de Juan Manuel García permitió conseguir un hecho que hasta el momento no había sido posible: la posesión definitiva de las tierras. El hecho permitió no sólo mantener el centro de entrenamiento sino también incrementar los bienes patrimoniales del club. Para que la CEAMSE accediera a vender las tierras fue necesaria la intervención de un contacto o "un amigo" influyente de García como el Gobernador de la Provincia de Buenos Aires, Alberto Sola. La vinculación de García con la máxima autoridad del Estado Provincial permitió la posesión definitiva de las tierras. ${ }^{12}$

La amistad instrumental, para Wolf (1980), ${ }^{13}$ es aquella en la que cada uno de los componentes actúa como un potencial eslabón de conexión con otras personas ajenas al vínculo con una utilidad práctica en el ámbito de la influencia política y económica. A diferencia de la amistad emocional, que va acompañada de una limitación del círculo social, la amistad instrumental sobrepasa los límites de los grupos ya existentes e intenta establecer cabezas de puente con nuevos grupos. La aceleración de un asunto legal o la obtención de un trabajo pueden darse gracias a la influencia personal de un conocido que tiene poder o que conoce a un tercero influenciable (WOLF, 1980, p. 30). Nos interesa establecer una analogía entre la amistad instrumental de Wolf y las relaciones que los dirigentes con posiciones jerárquicas y privilegiadas entablan entre sí en el marco de alianzas estratégicamente armadas, a partir de las cuales se crean contactos o puentes en beneficio de los involucrados, y especialmente en beneficio del club. Tener muchos contactos en varios lugares o tener "amigos" influyentes facilita la producción de canales de comunicación que son utilizados favorablemente por los directivos a favor de la institución.

El caso de Juan Manuel García ilustra cómo a partir de la posición privilegiada (como dirigente del CAJU y referente del sindicato y de la

11 "Coordinación Ecológica del Área Metropolitana Sociedad del Estado" es una empresa encargada del transporte, de la disposición y la recuperación de los residuos. La disposición final de la basura se realizaba a través del relleno sanitario en un cinturón costero donde el CAJU le alquilaba a la CEAMSE un tramo de sus tierras para formar dicho complejo de entrenamiento.

12 Más allá de las diferencias en las trayectorias de ambos dirigentes políticos, García y Sola provienen del Partido Justicialista (PJ).

13 WOLF, Eric Relaciones de parentesco, de amistad y de patronazgo en las sociedades complejas. In: BANTON, Michael (Org.). Antropología social de las sociedades complejas. Madrid: Alianza, 1980. 
CGT), con múltiples conexiones y contactos con los más altos niveles de la jerarquía del Estado Provincial, fue posible mediar exitosamente consiguiendo el título de posesión definitiva de las tierras para el beneficio de la institución. El hecho, que tuvo una cobertura en varios espacios mediáticos y publicaciones en el ámbito del club, repercutió positivamente en el balance anual de la gestión del presidente Facundo Ramos. Este dirigente tuvo la posibilidad de poner en juego la red de relaciones influyentes y los puentes que éstas construían en pos de la obtención del predio. Cuando Hermitte y Bartolomé plantean las características de los procesos de "articulación social", expresan que éstos están constituidos por "aquellos mecanismos conectivos que funcionan entre los distintos componentes de un sistema social y que canalizan la transmisión de la acción social y la circulación de bienes y servicios" (HERMITTE; BARTOLOMÉ, 1977, p. 10). ${ }^{14}$ La propuesta de los autores es la comprensión de los circuitos concretos que interconectan actores y/o unidades dentro de sistemas de carácter más amplio. En el caso del CAJU, la institución quedó conectada con el Estado Provincial a través de la articulación de un hombre influyente que se encontraba posicionado simultáneamente en distintas esferas de actuación, la deportiva y la sindical.

Por otra parte, la cercanía entre la institución deportiva y el municipio de Pontevedra, basada en el afecto y la pasión sentidos hacia el CAJU por el Intendente y algunos funcionarios del gobierno local, era una "situación social específica" que agilizaba la comunicación y la canalización de los recursos y favores en ambos sentidos. Hermitte y Herrán describen los procesos de articulación social como la relación entre un sector del sistema social y el todo del que forma parte. Este tema, según los autores, puede ser mirado con distintos enfoques: indagar acerca de los roles y las posiciones que facilitan la comunicación y la canalización de favores y recursos entre ambas esferas, las situaciones sociales específicas en las que se manifiestan frenos o, por el contrario, una agilización de la articulación, y la perspectiva histórica que ilustra las sucesivas etapas del proceso articulatorio (HERMITTE; HERRÁN, 1977, p. 238). ${ }^{15}$

14 HERMITTE, Esther; BARTOLOMÉ, Leopoldo. Introducción. In: (Org.). Procesos de articulación social. Buenos Aires: Amorrortu, 1977.

15 HERMITTE, Esther; HERRÁN, Carlos. Sistema productivo, instituciones intersticiales y formas de articulación social en una comunidad del noroeste argentino. In: ; BARTOLOMÉ, Leopoldo. (Org.). Procesos de articulación social. Buenos Aires: Amorrortu, 1977. 
Durante su primera presidencia en el club, hacia diciembre de 2006, Facundo Ramos comenzó un proyecto monumental: la construcción de un nuevo estadio. Cuando se inició la obra, la apertura del recinto quedó programada para agosto de 2008. Sin embargo, los trabajos de ejecución del estadio se retrasaron y el proceso de construcción quedó enmarcado en "el tiempo de la política". Según Palmeira y Heredia (1997), ${ }^{16}$ esta categoría describe un tiempo cuasi indefinido que está relacionado con el momento en el que los "políticos profesionales comienzan a hacer política". En ese marco, "los profanos" perciben "la política" como una dimensión externa y amenazadora o contaminante de su cotidiano. En nuestra investigación retomamos la categoría para sugerir que refiere a un "tiempo especial" en el que la política electoral adquiere mayor visibilidad y notoriedad en las conversaciones, las situaciones y los lugares de la vida cotidiana del club. En nuestro caso, "el tiempo de la política" no se constituye como un tiempo diferente, discontinuo, del que transcurre cuando los dirigentes no están sumergidos en la campaña electoral. El tiempo de la política es un momento en el que los acercamientos y las oposiciones en la arena de lucha se dinamizan.

Unos meses antes de las elecciones a disputarse en diciembre de 2008, Walter Montero fue nombrado por el presidente del CAJU: presidente de la comisión de obra de acceso y estacionamiento del nuevo estadio. Walter Montero tenía una particularidad: era el Secretario de Obras Públicas del municipio de Pontevedra y formaba la primera línea del Estado comunal. El ingreso de Montero para ocupar un cargo en el CAJU implicaba el ejercicio de una doble función, como dirigente deportivo y como funcionario del municipio. La doble pertenencia de Montero afianzaba la articulación entre ambas esferas: el club y el municipio.

Entre las formas que permiten la captura de recursos en beneficio de una población, Hermitte y Herrán mencionan la que involucra a funcionarios del aparato formal del Estado con clubes sociales y deportivos con los que se identifican. En sus ejemplos, los autores comentan que un funcionario, que cumple un papel central en la adjudicación de los recursos, puede generar un tratamiento preferencial con el club de pertenencia

16 PALMEIRA, Moacir; HEREDIA, Beatriz. Política ambigua. In: BIRMAN, Patricia et al. (Org.). O mal à brasileira. Rio de Janeiro: UERJ, 1997. 
y un freno de las ayudas para el club que es su rival directo (HERMITTE; HERRÁN, 1977, p. 252), ${ }^{17}$ Frente a los recursos del Estado, que siempre son escasos en relación con las demandas y las necesidades de la población, el articulador procura la situación favorable para el grupo social con el que se identifica desviando recursos económicos y servicios de los distintos estamentos (Estado Nacional, Provincial o Municipal). ${ }^{18}$

La articulación de Montero permitió, por un lado, la resolución de los problemas burocráticos, el asesoramiento en el desempeño de la construcción del estadio, el desvío de recursos para mejorar los accesos viales al mismo, entre otros asuntos, y por otro lado, el sostenimiento de los intereses políticos del Intendente de Pontevedra de llegar a todos lados y estar en contacto con la gente que se congregaba en el club de fútbol con más convocatoria del municipio. Ejercer un cargo en el club posibilitaba también la ampliación de la plataforma desde la cual se hacía publicidad de los programas del gobierno municipal.

El ingreso del Secretario de Obras y Servicios Públicos o, como decían entre los dirigentes, de gente de la municipalidad materializaba la conformación de la alianza entre el presidente del CAJU y el Intendente municipal. La posición de Montero era estratégica en razón de los servicios múltiples - de asesoramiento, ejecución de trámites burocráticos, etc. - que le podían encomendar con facilidad. Por otra parte, él gozaba de la publicidad que le brindaban ambos cargos que estaban emparentados y relacionados con la exposición pública. Una de las funciones de Montero, tanto en el club como en el municipio, era explicar públicamente el avance de los proyectos y las obras en ambas esferas.

Como dice Bezerra (1999), ${ }^{19}$ mostrar "la utilidad pública" de las obras permite a los políticos construir o conservar una posición de liderazgo. En nuestro caso, exhibir la capacidad de construir en pos del impulso del fútbol es un recurso con el cual se gana reconocimiento político en el

17 HERMITTE, Esther; HERRÁN, Carlos. Op. cit., 1977.

18 Los hinchas de la Asociación Atlética de Pontevedra (AAP), el rival histórico del CAJU, consiguieron el préstamo de un terreno donde construyeron un centro recreativo. La cesión definitiva de las tierras debía darse con la autorización del Intendente que, según los hinchas de la AAP, trabó la operación porque era del CAJU. Este caso podría ser una de "las situaciones sociales específicas en las que se manifestaban frenos de la articulación".

19 BEZERRA, Marcos Otávio. Em nome das "bases". Política, favor e dependência pessoal. Rio de Janeiro: Relume Dumará, 1999. 
mundo de los dirigentes y entre los hinchas. El desarrollo del patrimonio edilicio es un proceso que está impulsado por los dirigentes para beneficiar a los socios, que vuelve a los ellos en forma de crédito y prestigio político. Especialmente, en torno a la construcción del nuevo estadio, el emprendimiento implicaba la evaluación positiva del desempeño de Facundo Ramos como presidente del club y la reconversión de ésta en recurso político en época de elecciones.

La inauguración del estadio se realizó el 25 de noviembre de 2008, casi un mes antes de las elecciones. En rigor, el acto no fue una inauguración sino una presentación de las obras del estadio. El recinto no estaba terminado. La ceremonia recibió el sello de ser un acto político en tiempos electorales. Mientras los dirigentes de la oposición utilizaban el proyecto del estadio y la preinauguración como medios para fustigar la imagen de los dirigentes oficialistas, para éstos el estadio era el medio más eficaz para exponer las acciones realizadas en pos de los hinchas. Los dirigentes pudieron "hacer campaña" sobre los tramos finalizados de la obra - no concluida - en una fiesta que congregó a miles de hinchas. En la última parte de la ceremonia, se desarrolló un mini campeonato de fútbol en el que se enfrentaron equipos con jugadores actuales y glorias del pasado y personalidades de la televisión que eran confesos hinchas del club. Allí se evidenciaron claramente los alineamientos en tiempos electorales. Un invitado especial que se lució en el campo de juego, ante el público y la televisión, fue el Intendente del municipio de Pontevedra.

El máximo mandatario del poder local brindó su apoyo a Ramos en el "tiempo de la política". Él solía mostrarse públicamente en los actos políticos en plena campaña electoral, especialmente cuando los encuentros entre los dirigentes y los hinchas se realizaban en clubes o espacios dentro del municipio. La adhesión del Intendente a la candidatura de Ramos implicó en ciertos momentos la toma de la palabra en los actos de campaña para incentivar a los socios a votar por la fórmula del presidente, en la que un funcionario de su gobierno - Walter Montero - participaba como candidato a una vicepresidencia. Podía verse en dichos eventos a empleados municipales y a vehículos con el sello de la municipalidad de Pontevedra en el exterior de los lugares de campaña.

Observamos que para ganar la competencia electoral, los dirigentes procuran ayudas, consiguen adeptos, establecen amistad y entran en inte- 
racción con individuos influyentes. A través de dichos acercamientos, ellos forman, como define Soprano (1999), ${ }^{20}$ redes de alianza y clientela. Los dirigentes deportivos que luchan por el poder político y entran en tensión conflictivamente, tejen relaciones y forman facciones con individuos que se encuentran en condiciones de igualdad o en condiciones asimétricas. Facundo Ramos sumó a su red de relaciones a Juan Manuel García, reconocido sindicalista de nivel nacional, para disputar las elecciones de abril de 2005; hacia fines de 2008, nombró como dirigente a un funcionario del gobierno local, quién además lo acompañó en la fórmula para las elecciones de ese mismo año. Los sindicalistas y los funcionarios de la municipalidad, que eran agentes representativos de otros campos, se convirtieron en aliados políticos de Ramos

\section{El juego político con los hinchas}

Las elecciones en el CAJU generan un operativo que incluye el despliegue de personas y recursos, destinados a obtener la mayor cantidad de votos a favor de un candidato. Si bien es un hecho habitual pedirles a los socios que lleven gente a votar, hay personas estratégicamente seleccionadas para concretar este objetivo. Llevar gente a votar es un mecanismo de una maquina aceitada donde cada uno tiene una función asignada.

Los encargados de realizar esta tarea en apoyo de Facundo Ramos en la elección de 2008 fueron los hinchas que se identificaban con la barra vieja. ${ }^{21}$ Este sector estaba formado por los hombres que integraron la barra

20 SOPRANO, Germán. Formas de organización y socialización en un partido politico. Etnografía sobre facciones, alianzas y clientelismo en el peronismo durante una campaña electoral. Tesis (Doctorado) - Universidad Nacional de Misiones. Inédita. Misiones: Universidad Nacional de Misiones, 1999.

21 Estaba constituida por hombres que habían integrado la barra en la década del setenta, ochenta y noventa. En este trabajo analizamos solamente la participación de un sector de estos hombres. En un trabajo más extenso hemos estudiado también la intervención en tiempos electorales de otros hinchas - los jefes de la barra actual, los hinchas influyentes del mismo grupo, otros hinchas con doble adscripción, etc. Ver MOREIRA, María Verónica. La política futbolizada: los dirigentes deportivos y las redes político-territoriales en Pontevedra. Tesis (Doctorado) - Universidad de Buenos Aires. Inédita. Buenos Aires: Universidad de Buenos Aires, 2010. 
en décadas pasadas cuando el líder era Ares. ${ }^{22}$ Ellos, junto a otros sectores de hinchas, pusieron en marcha un mecanismo particular: cada uno con un tiempo de antelación (dos meses, aproximadamente) debía llenar una planilla con el nombre y el número de carnet de los socios que iban a votar a favor de Ramos. Todo socio debe tener la cuota del club al día si quiere votar. Así, los hinchas se encargaron de identificar a los socios que tenían cuotas impagas para saldar la deuda. Esto es conocido como el blanqueo de la cuota o el carnet. A su vez, de la misma planilla los hinchas obtuvieron una pequeña lista de los socios que necesitaban un automóvil para trasladarse a la sede social del club, donde iba a realizarse la votación. A esos afiliados estaban destinados los autos de alquiler. Los socios arribaban con chofer o por sus propios medios y si adeudaban cuotas, el hincha que los había convocado ponía en cero la cuenta. Cada uno de los hinchas manejaba personalmente y con autonomía a los socios que formaban su planilla.

Ares, que había dirigido la barra en las décadas del ochenta y noventa, era respetado por sus ex compañeros por su carisma y valor. Éste era empleado del club y se identificaba con una agrupación política que se alió a Ramos cuando el dirigente ganó la primera presidencia. Hacia fines de 2008, Ares solicitó una ayuda a un sector reducido de los ex integrantes de la barra para armar las planillas de socios. Los seguidores más fieles de Ares usaron sus contactos por el pedido expreso del que fuera su jefe y lo hicieron porque la lealtad era hacia él y no hacia Ramos. Una motivación importante para llevar gente a votar era la lealtad y el respeto sentidos por el emblemático líder. A pesar de la asimetría dentro de la hinchada, donde cada uno tenía una posición en la estructura jerárquica, los hinchas se aliaron a Ares para que éste y su agrupación política ganaran en el juego electoral.

Un hincha que intervino activamente en el armado de las planillas llevando gente a votar fue Misterio. Este hincha era un hombre de cuarenta años de edad que había ocupado en la hinchada lo que se conoce como pri-

22 En otro estudio analizamos el orden social de la hinchada en función de dos ejes: una estructura jerárquica formada por jefes, hombres influyentes y tropa; y una clasificación territorial basada en los barrios que agrupan a hinchas provenientes de un mismo lugar, los cuales se congregan alrededor de sus referentes. Como mencionamos en otra nota, la muestra de coraje entre los hinchas es un bien altamente buscado y deseado que genera prestigio. Los hinchas que cumplen funciones de dirección han probado que tienen valor en las peleas o en las situaciones de conflicto. Ver MOREIRA, María Verónica. Aguante, generosidad y política en una hinchada de fútbol argentina. Avá Revista de Antropología, Posadas, Misiones, n. 12, p. 79-94, marzo 2008. 
mera línea, es decir, el círculo íntimo del jefe. Misterio vivía en un barrio de Pontevedra y había sido el referente de un grupo de 50 hinchas que vivían en el mismo lugar. Pese al paso de los años, Misterio siguió siendo fiel a su antiguo líder. Para las elecciones de 2008, él inscribió en la planilla de electores a 100 socios entre familiares, amigos, vecinos e hinchas. Todos formaron la red que Misterio movió en las elecciones. Según Misterio, los dirigentes buscan a los hinchas de la barra vieja y la barra porque: (ellos) tienen liderazgo, arrastran gente. Esos son los que te hacen ganar las elecciones. El líder de un barrio te aporta votos. El líder no necesita de afiches, carteles. La red social de Misterio era el producto de relaciones personalizadas construidas en base a vínculos fuertes y cercanos - como los que signaban la unión con sus parientes políticos, de sangre y amigos íntimos -; o más débiles y distantes - como los que tenía con sus vecinos y algunos hinchas de su mismo barrio. Los hinchas como Misterio ponían en juego su propio prestigio y respeto como antiguos referentes de sus barrios. Ellos también esperaban que los llamados fueran respondidos positivamente por los hinchas que estuvieron a su cargo.

Mostrar el capital social no es un mecanismo exclusivo de los hinchas. Mover la red social es una acción valorada que los socios politizados muestran para tener una oportunidad en la elección interna de las listas de candidatos. Así, abonando la teoría sobre la importancia de poner en juego el capital social, Mabel Moreno, que integró la Comisión Directiva entre 2005 y 2008, explicó que para hacerse fuerte en el mundo masculino de la política tuvo que convencer a las mujeres y recorrer el padrón. Como dirigente debía contar con una cantidad de socios que pudieran acudir a su llamado en el período de elecciones. Era central mostrar que tenía: 30, 50, 60, 70 personas que respondían por ella. Una semana después del primer encuentro con Mabel y un mes antes de las elecciones de diciembre de 2008, se encontraba visiblemente exaltada y conmovida. Con enojo habló del cierre definitivo de la lista de candidatos que iban a acompañar a Facundo Ramos y de la presencia en un primer plano de gente de la municipalidad. Mabel que era vocal titular de la Comisión Directiva, aparecía en la nueva lista como Revisor de Cuentas Suplente, un papel de menor jerarquía. Yo quedé (entre los candidatos) dicen que porque Facundo me defendió. Golpeándose el pecho, con vehemencia y orgullo repitió varias veces: ¡yo tengo mi tropa, tengo mi gente! 
Mover gente, tener socios, arrastrar, tener una tropa, reunir son acciones que incrementan y fortalecen la posición de los interesados en hacer y participar de la competencia política en la institución deportiva. Los hinchas de la barra vieja - así como los jefes de la barra, los hinchas que dirigen pequeños grupos, etc. - tienen seguidores naturales por los lugares que ocupan o que llegaron a ocupar. Es curioso observar cómo los hinchas que son estigmatizados generalmente por el sentido común hegemónico como "bestias", "animales", "soldados" y "mercenarios" se convierten en participantes centrales durante las elecciones. El capital social, que es altamente estimado en tiempos electorales, es el que muestran e intercambian los hinchas con los dirigentes. Lejos de la irracionalidad de sus prácticas y de la manipulación de los políticos como si fueran objetos, los hinchas participan exitosamente en el juego de la política del club. Algunos logran un empleo en la institución, más contactos que se suman a su red social, ayudas para solucionar problemas, aumentan su prestigio, etc.

Ares ingresó a una agrupación política de la mano de un dirigente y amigo suyo de nombre Pocho Domínguez. Pese a la labor que Domínguez había realizado en la gestión directiva entre 2005 y 2008, se especulaba que para las elecciones siguientes iba a quedar fuera de los candidatos de la Comisión Directiva. Frente a la incógnita de si Pocho se presentaba como candidato y frente al rumor de un posible despido de Ares de su empleo en el club, los hinchas suspendieron los llamados telefónicos a los socios que integraban la planilla de contactos. La cadena de lealtades fundada en la amistad y el compañerismo entre los hinchas se puso de manifiesto por este conflicto. Así, el apoyo político dado a Ares y el trabajo invertido en el proceso electoral estuvieron estimulados por un sentimiento de pertenencia a un colectivo de hinchas con una historia común y, como dijo Misterio, por la lealtad y el respeto hacia el jefe de ese grupo.

Los hinchas por su reputación se convierten en un eslabón central en la trama electoral. Ellos son articuladores de conjuntos sociales distintos y tienen la capacidad de movilizar recursos entre los sectores que conectan. Cuando hay elecciones, "los mediadores" movilizan los votos de los afiliados hacia los candidatos y consiguen de éstos favores para los electores (entradas para un partido, el banqueo del carnet, un trabajo, contactos). Soprano $(1999)^{23}$ explica que la posición estratégica en la que se encuentra 
el mediador, a partir de la cual conecta dos mundos diferenciados y controla las vías de acceso a los recursos (bienes y servicios para los que votan y votos para los candidatos), le otorga poder en ambas redes de relaciones políticas personalizadas. El mediador no es simplemente un intermediario que facilita la circulación de recursos entre posiciones asimétricas entre el patrón/candidato y sus clientes. Él es patrón y cliente al mismo tiempo (patrón de la gente que él moviliza directamente y cliente de un patrón con el que mantiene una relación personalizada pero desigualdad). Como dice Landé (1977), ${ }^{24}$ en una pirámide una persona puede ser cliente y patrón de personas distintas. Para Soprano (2002), ${ }^{25}$ la prueba empírica de que un "puntero" 26 es un patrón, y no un simple "broker" que media entre dos mundos, puede identificarse cuando "rompe" relaciones con su patrón y "arrastra" consigo su red de clientela que le responde en términos de lealtad. Este proceso se observó con claridad en el caso de Facundo Ramos, Pocho Domínguez, Ares y los hinchas de la barra vieja cuando los dos primeros disputaban los cargos en la Comisión Directiva en 2008. Frente al intento de sacar de la lista de candidatos a Domínguez, Ares solicitó a sus seguidores abandonar los llamados a los socios que iban a votar por Ramos. Para los hinchas de la barra vieja, el auténtico merecedor de la deferencia y el respeto no era Ramos ni Pocho sino Ares. El antiguo jefe de la barra era el que tenía el poder de arrastrar a los hinchas, incluso a aquellos que también tenían capital social. Como sugiere Auyero (2001), ${ }^{27}$ lo distintivo en los mediadores es la cantidad acumulada de capital social que se traduce como la cantidad de recursos derivada de las conexiones y de la pertenencia a ciertos grupos. Es decir, la acumulación que se promueve gracias a las

24 LANDE, Card. The dyadic basis of clientelism. In: SCHMIDT, Steffen et al. (Org.). Friends, followers and factions: a reader in political clientelism. Berkeley: University of California Press, 1977.

25 SOPRANO, Germán. A favor de una etnografía sobre clientelismo político y peronismo. Desarrollo Económico, Buenos Aires, v. 42, n. 167, p. 483-488, octubre-diciembre 2003.

26 Algunos hinchas y dirigentes hablan con términos tales como puntero o referente para indicar los casos de personas que tienen la capacidad de juntar y volcar el caudal de votos hacia un candidato. Dice Masson que "referente y puntero político son dos formas de denominar a los mediadores entre la figura del candidato y la del elector, aunque ambos no tienen exactamente el mismo significado. Esta relación política de mediación es nombrada en términos acusatorios como clientelística" Ver MASSON, Laura. La política en femenino. Género y poder en la provincia de Buenos Aires. Buenos Aires: Antropofagia, 2004. p. 122.

27 AUYERO, Javier. La política de los pobres. Las prácticas clientelistas del peronismo. Buenos Aires: Manantial, 2001. 
conexiones con parientes, amigos, conocidos y otros contactos obtenidos por pertenecer y circular en distintas asociaciones y organizaciones.

Soprano (1999) define al "puntero" como aquel que tiene un volumen de clientes, recursos materiales y simbólicos y un reconocimiento público de un patrón. Lejos del esquematismo "patrón/mediador o broker/ cliente", el clientelismo:

[...] debe ser abordado en términos de redes de relaciones diádicas, integradas por individuos de igual y/o de desigual poder y jerarquía social, que establecen relaciones de reciprocidad simétrica y/o asimétricas. Un análisis de relaciones diádicas - patrón/cliente - estructuradas en redes de alianza y clientela resultaría más adecuado (SOPRANO, 1999, p. 243). ${ }^{28}$

En nuestro caso, Ares era un mediador que respondía al llamado de Domínguez, con el que supo dar los primeros pasos en la vida institucional del club. En otro tiempo, supo ser una especie de "patrón" de los hinchas con quienes tenía relaciones personalizadas y asimétricas fundadas en un sistema de intercambios recíprocos. ${ }^{29}$ En las elecciones de 2008, Ares llamó a sus antiguos "clientes" para mancomunar esfuerzos y volcar el caudal de votos hacia Facundo Ramos. La reciprocidad entre el antiguo líder de la barra y los hinchas se mantuvo después de las elecciones a pesar de que por ejemplo - Misterio no consiguiera el empleo estable que precisaba en la institución. Esto puede entenderse si pensamos que el intercambio entre las partes no respondía a un simple canje de "favores x votos" ni a una instancia efímera que proponía "el tiempo de la política". Las relaciones amistosas y cercanas continuaron entre Ares y los hinchas después del período electoral.

Finalmente, cabe aclarar que la barra actual en su totalidad (suman 250 hombres) no funciona como una clientela estable de un dirigente, $y$ que los hinchas convocados para participar de los procesos políticos son los que conservan puestos de conducción. La barra no es una clientela estable porque durante el tiempo electoral puede dividirse en facciones que apoyan

28 SOPRANO, Germán. Op. cit., 1999.

29 En el marco de la hinchada se desarrolla un sistema de intercambios mutuos muy complejo que incluye la asistencia en casos de detención policial, hospitalización, entradas, micro, comida, etc. a cambio de aguante, fidelidad en cada partido, respeto a los líderes, etc. 
a candidatos distintos. Esta situación se expuso durante las elecciones de 2005 cuando los jefes de la barra apoyaron a Minas Akiam, mientras que la facción conocida como los sindicalistas apoyó a Facundo Ramos. Este grupo reducido de hinchas apoyó a Ramos porque, como vimos, el titular del sindicato, Juan Manuel García, formaba parte de la lista de representantes de socios y su hijo Pedro figuraba como candidato a vocal titular de la Comisión Directiva. La ayuda de estos hinchas se basaba en el sentido de pertenencia a un espacio común y en la fidelidad a los líderes del sindicato.

Puede suceder que los jefes de la barra apoyen a un candidato y en la elección siguiente trabajen a favor de otro dirigente (en 2008 brindaron su apoyo a Ramos que le ganó nuevamente a Akiam). Este y otros ejemplos muestran que los apoyos en un sentido u otro dependen de las lealtades, los arreglos y las negociaciones que se crean y/o refuerzan en el período de elecciones. El proceso es complejo y dinámico y da como resultado lo que Mayer (1980) $)^{30}$ llama "cadenas de apoyo o conjuntos de acción" que se arman en torno a ciertos individuos que son aquellos que se caracterizan por la capacidad de reunir y arrastrar en apoyo a un candidato en particular. Mayer (1980) explica cómo los conjuntos de acción, que tienen como telón de fondo las redes sociales, producen agrupamientos de individuos en torno a un objetivo que se promueve desde un ego o un centro. El proceso de formación de un conjunto de acción o de una facción sucede en el tiempo de elecciones cuando un candidato promueve a través de sus contactos e influencias el apoyo político para triunfar en las elecciones.

\section{Palabras finales}

¿Cuáles son los mecanismos de ascenso, lucha y permanencia de los dirigentes en los clubes de fútbol? ¿Cuáles son las alianzas que ellos realizan para efectivizar y mantener el control? ¿Cuál es el peso y la participación de los hinchas en los procesos políticos electorales? ¿Cómo son las relaciones

30 MAYER, Adrian. La importancia de los cuasi-grupos en el estudio de las sociedades complejas. In: BANTON, Michael (Org.). Antropología social de las sociedades complejas. Madrid: Alianza, 1980 . 
con la política tradicional - de los sindicatos y el gobierno local?, ¿Cuáles son las formas que adquiere la política en el campo del fútbol?, éstas son algunas de las preguntas que guiaron la presente investigación.

Interpretamos en este trabajo que la intersección entre el mundo del fútbol y otros campos puede darse a través de las alianzas y las relaciones que los dirigentes deportivos del CAJU establecen con los funcionarios de Pontevedra y los referentes de un gremio en particular. Observamos también que el ingreso de individuos de campos ajenos al futbolístico permite la simultaneidad de actuación en distintos espacios y la circulación de favores en dirección al club. Cabe aclarar que reflexionar sobre la relación entre el fútbol y otros espacios sociales no tuvo como finalidad pensar en la existencia de universos estancos, autónomos y separados, sino en las múltiples intersecciones, densidades y profundidades de una realidad compleja que dividimos analíticamente. Asimismo, nos animamos a sugerir que los referentes de otras esferas se acercan al fútbol porque "lo popular" es un bien en disputa que se traduce en estima o simpatía. Acercarse a un deporte popular como el fútbol, que toca las fibras sensibles de la extensa comunidad de hinchas, es un mecanismo que permite la ganancia simbólica de los dirigentes y de los políticos profesionales cuando finalizan gestiones exitosas.

Un aspecto que surgió del análisis es cómo los sentimientos y las afinidades futbolísticas ayudan en la construcción de puentes y la circulación de bienes; cómo las inclinaciones deportivas de los políticos de la municipalidad y del sindicato juegan a favor de los dirigentes de turno y en beneficio del CAJU. En la historia del fútbol nacional se multiplican los casos de clubes que han sido favorecidos por la intervención de una personalidad influyente afín a la entidad. Entre los casos conocidos en Argentina, podemos recordar finalmente aquí la construcción del estadio de Racing Club. Éste llevó desde su fundación el nombre Presidente Juan Domingo Perón. El estadio habría sido un emprendimiento realizado "con los fondos del Estado" por la mediación del Ministro de Hacienda del gobierno peronista, Ramón Cereijo, que era un hincha fanático de la institución. La relación estrecha entre los dirigentes del club y los referentes de la política nacional quedó materializada con la ubicación de los bustos de Juan Domingo Perón y de Eva Duarte de Perón en la entrada de la sede social.

Observamos que los hinchas también son parte de la arena donde luchan los dirigentes. Los (ex)líderes y (ex)referentes de la hinchada ingre- 
san al universo político no como sujetos ajenos y extraños. Ellos encarnan una de las formas de hacer política que no es siempre ni necesariamente el ejercicio de la violencia (intimidación, protección, amenazas) sino la puesta en práctica del carisma, la exposición de poder, la seducción, etc. Ellos, que son o fueron patrones en su juego de poder en la hinchada, se convierten en mediadores o enlaces de grupos sociales distintos durante el proceso electoral. En torno a los hinchas, sugerimos que lejos de la irracionalidad, ellos saben jugar en el campo de los dirigentes exponiendo un bien disputado en las elecciones: el capital social. Por otra parte, analizamos que las relaciones asimétricas o clientelares de los hinchas con sujetos ubicados en una posición superior de la facción no indican necesariamente una motivación instrumental (un intercambio de favores por votos) sino también razones asociadas a un sentimiento de pertenencia, fidelidad y lealtad.

Finalmente, notamos que los individuos en su afán de formar redes de alianza y clientela, desarrollan prácticas que no difieren en demasía de las prácticas que tienen lugar en el espacio de la política tradicional: llevar gente a votar, reunir, arrastrar, formar facciones, buscar adhesiones, realizar campañas electorales, prometer obras de interés público, etc. Tener en cuenta la continuidad de las prácticas entre estos dos espacios también es una forma de explicar "la relación en el fútbol y la política". A su vez, dicha continuidad no hace más que recordar la artificialidad de la construcción de los campos.

Recebido em julho de 2012. Aprovado em agosto de 2012. 